\title{
Estimation and Influencing the Variability of Yield Losses in Wheat
}

\author{
S. Patel ${ }^{1 *}$, Y. Gharde ${ }^{2}$ and K. K. Pandey ${ }^{3}$ \\ ${ }^{1}$ Department of Agricultural Statistics and Social Science, College of Agriculture, IGKV, \\ Raipur, India \\ ${ }^{2}$ Directorate of Weed Research, Jabalpur, India \\ ${ }^{3}$ S.K. College of Agriculture and Research Station, Kawardha, India \\ *Corresponding author
}

\section{A B S T R A C T}

\section{Keywords}

Dry weight, Weed density, Wheat, validation

Article Info

Accepted:

20 May 2018

Available Online:

10 June 2018
The present study was carried out to make a suitable forecast model that predicts yield loss occurred due to weeds in wheat crop. The data were taken from the annual report of AICRP-WM centres. Gwalior and Pusa are the two centres in which the work has been carried out. Weed density and weed dry weight were two weed infestation measurements that were considered for model fitting. Simple linear, quadratic and cousens (1985) proposed hyperbolic model were tested. In AICRP-WM Gwalior, for independent variable weed density simple linear model and for weed dry weight quadratic model was find the best fit model but the validation of models indicates these model does not predict the yield loss accurately. In data of AICRP-WM centre Pusa for independent variable weed density, simple linear model and for weed dry weight quadratic model was find the best fit models. Validation of these models shows that the above mention models were accurately predicting the yield loss.

\section{Introduction}

In India, the agriculture sector occupies a vital position in overall Indian economy. Currently, India is one of the largest producers of cereals and grains. Wheat (Triticum spp) is most important cereal crops in all over of world 80 million people consumed wheat every day all over the world (CIMMYT site) and alone provides $20 \%$ calories and protein. The demand of wheat in 2050 is predicted as $70 \%$ increase from the present situation (CIMMYT site). In India, wheat is grown in 30.2 million hectares area and production of 93.50 million tonnes during 2015-16. Hence, wheat is the second most important crop grown in India in terms of both area and production. India is the second largest producer of wheat after china But the productivity of wheat is low (3093 $\mathrm{kg} / \mathrm{ha}$ ) as compared to the world's average $(3314 \mathrm{~kg} / \mathrm{ha}$ ) (Agricultural statistics at a glance, 2016).

It was found that the yield loss occurred due to insect, weeds and disease is $27.90 \%, 37.02 \%$ and $15.6 \%$ respectively in rice crop (Mondal et al., 2017). In direct-seeded condition, rice experienced $15-66 \%$ potential yield losses due to weeds whereas, in wheat, $16.5-43 \%$ potential yield loss were observed due to weed 
infestation in farmers' field (Gharde et al., 2018). In another study, it was estimated that in India the overall yield loss in different crop due to weed infestation is around $36.5 \%$ (Bhan et al., 1999). In another study, 20 to 28 billion economic losses were estimated due to weed infestation in India (Sahoo and Saraswat, 1988; Sachan, 1989). More recently, in a scientific study, Gharde et al., (2018) reported an annual loss of about 11 billion USD in 10 major crops due to weeds alone. Hence, weeds may be considered as biggest threat to crop production systems.

There are many predictive models to predict the yield loss and which uses different independent variable such as relative leaf area (Cousens 1985), period between crop and weed emergence (Consens et al., 1987), weed density (Spitters et al., 1983). The input like weed leaf area and time between crop and weed emergence make model more complex. Hence in the present study weed density and weed dry weight are used as independent variable.

The aim of the study is to develop yield loss predictive models based on the weed infestation measures for rice and wheat crops. The model will suggest the probable yield loss based on the measure of weed infestation at an early growth stage. For the purpose, it was planned to test and validate several linear and non-linear models to obtain a robust predictive model.

\section{Materials and Methods}

The multiyear data on weed infestation was taken on the study. These data was taken from the annual report launched by All India Coordinated Research Project on Weed Management centres. Two centres were considered for the study Gwalior and Pusa. The least square method was used to estimate the parameter of linear and quadratic model and non-linear least square method was used to estimate the parameter of Cousens (1985) proposed non-linear model. Coefficient of determination $\left(\mathrm{R}^{2}\right)$, Akaike information criterion (AIC) and Bayesian information criterion (BIC) was used for model selection.

\section{Calculation of Relative Yield Loss}

Yield loss in wheat crop due to different weed infestation was calculated as compared to yield of weed free plot. Relative yield loss gives the percentage yield loss due to specific weed infestation. The following formula was used to calculate the yield loss

$\mathrm{Y}_{\mathrm{L}}=\frac{\mathrm{Y}_{\mathrm{WF}}-\mathrm{Y}_{\mathrm{t}}}{\mathrm{Y}_{\mathrm{WF}}} \times 100$

Where

$\mathrm{Y}_{\mathrm{L}}$ : Relative yield loss

$Y_{\mathrm{WF}}$ : Yield of weed free plot

$\mathrm{Y}_{\mathrm{t}}$ : Yield of treatment plot

\section{Models used}

\section{Simple Linear Model}

Simple linear model was used to express the relation between the yield losses and weed population measure (Weed density and Weed dry weight). The equation of simple linear model is

$\mathrm{y}_{\mathrm{L}}=\mathrm{a}+\mathrm{bx}$

$\mathrm{y}_{\mathrm{L}}$ : yield loss

$\mathrm{x}$ : weed infestation measure

a: Intercept

b: Regression coefficient

\section{Quadratic model}

Quadratic model was used to express the curvilinear relationship between yield loss and 
weed population measure (weed density and weed dry weight). The equation of quadratic model is

$y_{L}=a+b_{1} x+b_{2} x^{2}$

$\mathrm{y}_{\mathrm{L}}=$ Yield loss

$\mathrm{x}$ : Weed infestation

a: Intercept

$\mathrm{b}_{1} \& \mathrm{~b}_{2}$ : Regression coefficients

\section{Hyperbolic models}

Cousens (1985) proposed two parameter model:

$Y_{L}=\frac{i N_{w}}{1+\frac{i}{m} N_{w}}$

Where

$\mathrm{Y}_{\mathrm{L}}$ : Yield loss

$\mathrm{N}_{\mathrm{W}}$ : Weed infestation measures

i: Competitive ability of the weed species m: Maximum expected yield loss.

\section{Results and Discussion}

Simple linear, quadratic and hyperbolic model was fitted in Gwalior with $80 \%$ dataset and
$20 \%$ data was used to validate the model. Weed density and weed dry weight was square root transformed data. The models were compared and simple linear model was found the best fit model. The coefficient of determination was $51.39 \%$. Summary of the result was given in the Table 1.which shows that both intercept and regression coefficient was highly significant at $1 \%$ level of significance. In model validation it was observed that the model did not predict the yield loss accurately.

To know the relationship between yield losses and weed dry weight above mentions models were fitted and it was found that quadratic model was the best fit model. The coefficient of determination was $51.59 \%$. The summary of the results was given in the table 1.2. In model validation it was observed that the quadratic model was not a good predictor for the yield losses.

Hence it was concluded that weed density and weed dry weight were not enough to forecast the yield loss in Gwalior with simple linear, quadratic and hyperbolic model. Some other factors might contribute to the yield loss which should be included in the form of the parameter in the model. Model validation is shown in the figure 1.1.

Fig.1 Validation of selected model for weed density and dry weight in gwalior

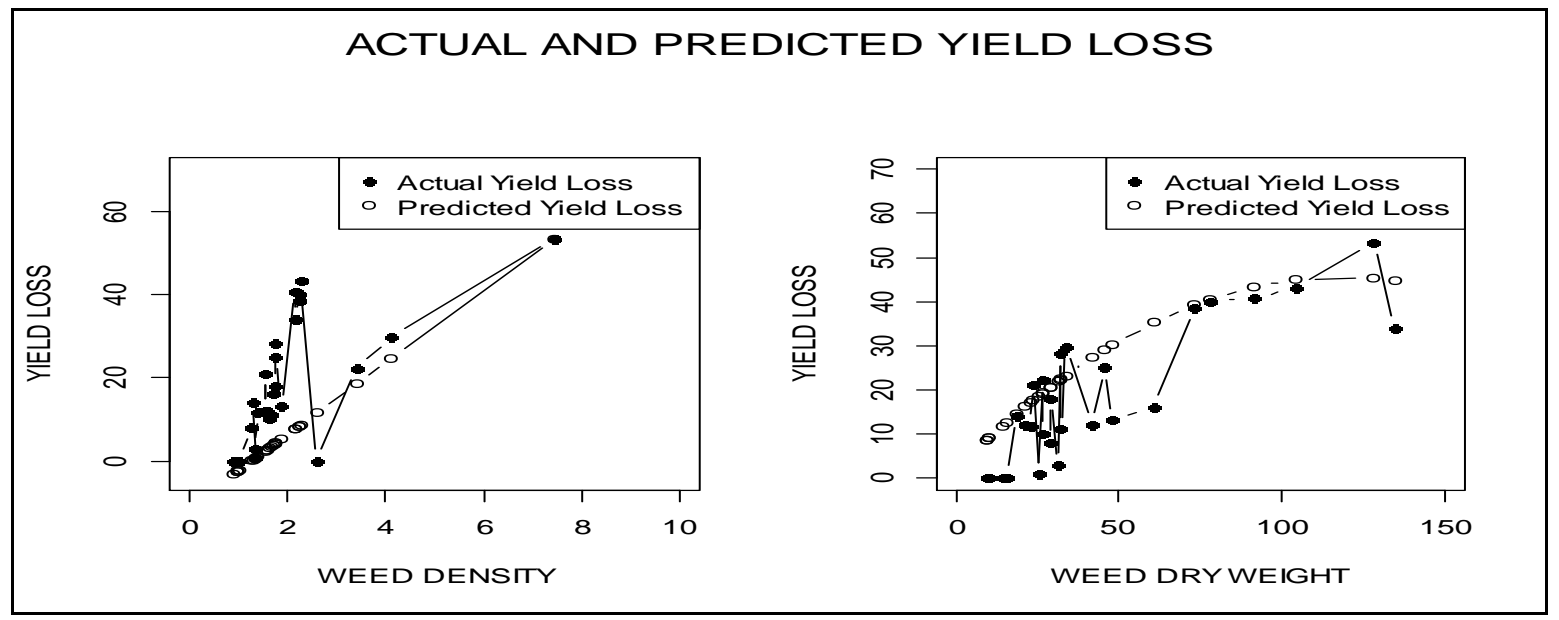


Fig.2 Validation of selected model for weed density and dry weight in Pusa

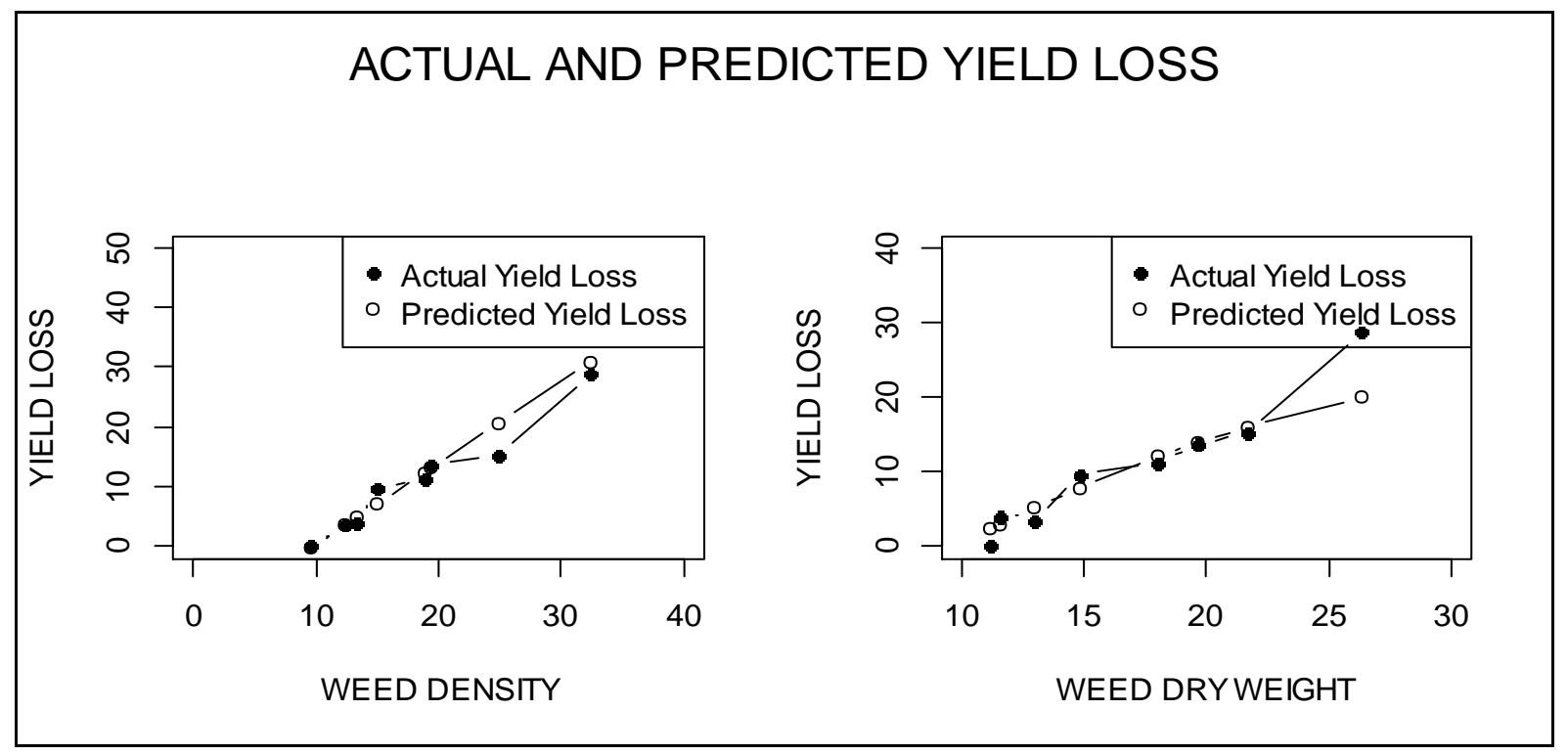

Table.1 Summary of the result simple linear model with weed density in Gwalior

\begin{tabular}{|c|c|c|c|c|c|c|}
\hline & Estimate & Std. Error & $\mathbf{t}$ value & $\operatorname{Pr}(>|\mathbf{t}|)$ & $\mathbf{R}^{2}$ & AdjR $^{2}$ \\
\hline Intercept(a) & -10.9266 & 2.8528 & -3.83 & $0.000211 * * *$ & 0.5139 & 0.5096 \\
\hline b & 8.6433 & 0.7908 & 10.93 & $<2 \mathrm{e}-16 * * *$ & & \\
\hline
\end{tabular}

Table.2 Summary of the result quadratic model with weed dry weight in Gwalior

\begin{tabular}{|c|c|c|c|c|c|c|}
\hline & Estimate & Std. Error & $\mathbf{t}$ value & $\operatorname{Pr}(>|\mathbf{t}|)$ & $\mathbf{R}^{2}$ & ${\text { Adj } \mathbf{R}^{2}}^{2}$ \\
\hline $\mathbf{a}$ & 1.697 & 1.987 & 0.854 & 0.395 & 0.515 & 0.507 \\
\hline $\mathrm{b}_{1}$ & 0.744 & 0.094 & 7.881 & $<0.001 * * *$ & & \\
\hline $\mathrm{b}_{2}$ & -0.003 & 0.0005 & -5.578 & $<0.001 * * *$ & & \\
\hline
\end{tabular}

Table.3 Summary of the result simple linear model with weed density in Pusa

\begin{tabular}{|c|c|c|c|c|c|c|}
\hline & Estimate & Std. Error & $\mathbf{t}$ value & P value & $\mathbf{R}^{2}$ & Adj R $^{2}$ \\
\hline $\mathbf{a}$ & -13.348 & 1.942 & -6.872 & $1.81 \mathrm{e}-07$ - $* *$ & 0.8675 & 0.8627 \\
\hline $\mathbf{b}$ & 1.367 & 0.101 & 13.538 & $8.23 \mathrm{e}-14$ *** & & \\
\hline
\end{tabular}

Table.4 Summary of the result quadratic model with weed dry weight in Pusa

\begin{tabular}{|c|c|c|c|c|c|c|}
\hline & Estimate & Std. Error & $\mathbf{t}$ value & $\mathbf{P}$ value & $\mathbf{R}^{2}$ & Adj $^{2}$ \\
\hline $\mathbf{a}$ & -19.63 & 7.722 & -2.543 & $0.017 *$ & 0.648 & 0.622 \\
\hline $\mathrm{b}_{1}$ & 2.309 & 0.758 & 3.044 & $0.005 * *$ & & \\
\hline $\mathrm{b}_{2}$ & -0.030 & 0.016 & -1.822 & 0.079 & & \\
\hline
\end{tabular}


The relationship between yield losses and weed density above mention models were fitted in pusa and in comparison of the models it was observed that the simple linear model was the best fitted model. The coefficient of determination of simple linear model was $86.75 \%$ and the AIC and BIC value was lowest among all models. In model validation it was observed that the simple linear model predict the yield loss accurately. The result of model validation was shown graphically in the Figure 1.2.

The same models were fitted with independent variable weed dry weight and it was found that quadratic model was the best fit models among all the models. The coefficient of determination of quadratic model was 64.81 which were not very good but in model validation it was observed that the quadratic model forecast the yield loss accurately. The result of the model validation was given in the Figure 1.2. Gharde et al., 2017 also found the same results in Directorate of weed research, Jabalpur

In AICRO-WM centre Pusa weed density and dry weight was accurately predicting the yield loss by simple linear model and quadratic model respectively but in AICRP-WM centre Gwalior none of the three equations was consistently able to forecast the yield loss with the help of weed density or weed dry weight. So much deviations was found between actual and predicted yield loss hence it was concluded that some other factor might be influencing the variability of yield losses such as time between crop and weed emergence.

\section{References}

Agricultural Statistics at a Glance 2016. Directorate of Economics \& Statistics, Department of Agriculture, Co-operation and Farmers Welfare, Ministry of Agriculture, Government of India, New Delhi

Bhan, V.M., Sushilkumar, Raghuwanshi, M.S., 1999. Weed management in India. IndianJ. Plant Prot. 17, 171-202.

Cousens, R., Brian, P., O'Donovan, J.T., O'Sullivan, A., 1987. The use of biologically realistic equations to describe the effects of weed density and relative time of weed emergence on crop yield. Weed Sci., 35: 720-725.

Cousens, R.O.G.E., 1985. A simple model relating yield loss to weed density. Appl. Bio, 107: 239-252.

Gharde Y., Singh P.K., Dubey R.P., Gupta P.K., 2018. Assessment of yield and economic losses in agriculture due to weeds in India. Crop Protection, 107:12-18

Mondalet al., 2017. Yield loss assessment of rice (Oryza sativa L.) due to different biotic stresses under system of rice intensification (SRI). Journal of Entomology and Zoology Studies 5(4): 1974-1980.

Rice in the world Retrieved from http://www.fao.org/wairdocs/tac/x5801e/x580 1e08.htm

Sahoo, K.M., Saraswat, V.N., 1988. Magnitude of losses in the yields of major crops due to weed competition in India.Pestic.Info. 14, 29.

Spitters, C.J.T., 1983. An alternative approach to the analysis of mixed cropping experiments. Estimation of competition effects. Neth. J. Agric. Sci., 31 (1): 1-11.

Wheat Research Retrieved from https://www.cimmyt.org/global-wheatresearch/

\section{How to cite this article:}

Patel S., Y. Gharde and Pandey K. K. 2018. Estimation and Influencing the Variability of Yield Losses in Wheat. Int.J.Curr.Microbiol.App.Sci. 7(06): 2966-2970.

doi: https://doi.org/10.20546/ijcmas.2018.706.349 